1 - ORIGINAL ARTICLE

WOUND HEALING

\title{
Otostegia persica extraction on healing process of burn wounds ${ }^{1}$
}

\author{
Amin Ganjali', Amir Sotoudeh ${ }^{\mathrm{II}}$, Amirali Jahanshahi'II, Mohammad Ashrafzadeh Takhtfooladi ${ }^{\mathrm{III}}$, Ali Bazzazan ${ }^{\mathrm{IV}}$, Nasim \\ Roodbari', Maryam Pourramezani Harativ \\ ${ }^{I}$ Assistant Professor, Faculty of Experimental Science, Kahnooj Branch, Islamic Azad University, Kerman, Iran. Design of the study, manuscript \\ writing.

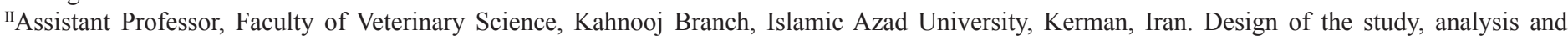 \\ interpretation of data. \\ IIIFellow PhD degree, Postgraduate Program in Veterinary Science, Department of Surgery, Faculty of Specialized Veterinary Sciences, Science and \\ Research Branch, Islamic Azad University, Tehran, Iran. Helped with technical procedures, collection and processing of study information. \\ ${ }^{\mathrm{IV}}$ Graduate student, Faculty of Veterinary Science, Garmsar Branch, Islamic Azad University, Semnan, Iran. Collection and processing of study \\ information. \\ ${ }^{\vee}$ Young Researchers and Elite Club, Kahnooj Branch, Islamic Azad University, Kerman, Iran. Analysis and interpretation of data.
}

\begin{abstract}
PURPOSE: To investigate if the methanolic extract of the Otostegia persica can accelerating healing process of burn wound because of its anti-inflammatory and antioxidant effects.

METHODS: Forty eight male Wistar rats were randomized into three study groups of 16 rats each. Burn wounds were created on dorsal part of shaved rats using a metal rod. In group I the burn wound was left without any treatment. Group was treated with topical silver sulfadiazine pomade. In group III, ointment containing the OP extract was administered. Skin biopsies were harvested from burn area on the 3rd, 5th, 14th and 21st days after burn and examined histologically.

RESULTS: Re-epithelialization in the control group and in group II was lower than in group III. Re-epithelialization in groups II and III was significantly different from that in the control group. On the 5th day of the experiment, we assessed lower inflammation in the burn area compared to control group. This means that the inflammation was suppressed by methanolic extract of OP. From day 5 to 14 ; the fibroblast proliferation peaked and was associated with increased collagen accumulation. It was obvious that angiogenesis improved more in the groups II and III, which facilitated re-epithelialisation.
\end{abstract}

CONCLUSION: Methanolic extract of Otostegia persica exhibited significant healing activity when topically applied on rats. OP is an effective treatment for saving the burn site.

Key words: Otostegia persica. Burn. Antioxidants. Rats. 


\section{Introduction}

Burn wound treatment is one of the challenges in the medical science. In burn area, excessive inflammation leading to increased vascular permeability, local tissue edema and neutrophil activation that cause local tissue damage ${ }^{1}$. New wound healing compounds are welcomed for accelerating regenerating process for its anti-inflammatory and antimicrobial effects. The interest in natural antioxidants has been increased considerably. As resources of natural antioxidants much attention has been paid to plants $^{2,3}$. The antioxidant activity of several Iranian plants has been reported ${ }^{4}$.

Otostegia persica (OP) that locally called «Golder» is an endemic medicinal plant growing in Kerman province in south of Iran $^{5,6}$. The aerial part of OP is reported to have high antioxidant activity which is related to the flavonoids ${ }^{7}$. It is used in Iran traditional medicine to treat malaria, fever ${ }^{5}$. It has also been used as analgesic in toothache ${ }^{6}$. The equeous extract of the OP is traditionally used as antihistaminic antispasmodic, anti-arthritis and antipyretic ${ }^{5}$. Additional biological screening of the methanolic extract has revealed strong antioxidant as well as antibacterial activities against various strains of Gram-positive and Gramnegative bacteria ${ }^{7,8}$. Recent studies indicated that the methanolic extract of its aerial parts has anti-diabetic effect ${ }^{6}$.

Despite many uses of OP, little data can be found about the wound healing effects of the plant. This prompted us to carry out an investigation for healing effects of OP on burn wound in rat. According to the experiments, it is determined that methanolic extract of the OP has antioxidant properties ${ }^{6}$.

We hypothesized that methanolic extract of the OP can accelerating healing process of burn wound through its antioxidant activity.

\section{Methods}

\section{Plant material}

The plant OP was collected from Kahnooj, Kerman province, Iran, in April 2013. The plant was identified by the Department of Botany of the Islamic Azad University, Kahnooj branch (BIAUK), Kerman. A voucher specimen has been deposited at the Herbarium of BIAUK.

Aerial parts of OP were finely powdered in a mill. 500 $\mathrm{g}$ of sample was percolated with methanol. The solvent was removed under reduced pressure at low temperature. The solvents were evaporated under the reduced pressure ${ }^{5}$.
OP extract was concentrated using rotary machine and dried with heating for 48 hours at $70^{\circ} \mathrm{C}$ in ban marry bath. In the next stage, $9 \mathrm{~g}$ dried extract was dissolved in $8 \mathrm{ml}$ of distilled water and $92 \mathrm{mg}$ Eucerin was added as preservative. The produced material was sterilized by ultraviolet and packed in $5 \mathrm{~g}$ tube.

\section{Laboratory animals}

Animals were kept in individual cages and they had free access to food and water, and were maintained in a controlled temperature $\left(24 \pm 2^{\circ} \mathrm{C}\right)$ and light cycle $(12 \mathrm{~h}$ light and $12 \mathrm{~h}$ dark).

The Experimental animal research laboratory at Islamic Azad University, Kahnooj branch, provided 48 male Wistar rats, weighing between 300 and $350 \mathrm{~g}$. The study was conducted in accordance with ethical standards and approved by our institutional animal research ethics board. The rats were randomized into three study groups of 16 rats each.

\section{Experimental protocol and burn model}

Burn wounds were created on dorsal part of shaved rats using a metal rod $\left(1.5 \mathrm{~cm}\right.$ diameter) heated to $80-85^{\circ} \mathrm{C}$ and exposed for $20 \mathrm{~s}^{9}$

In group I (control group), the burn wound was left to secondary healing without any treatment. In group II, the burn was treated with a twice-daily application of topical silver sulfadiazine pomade. In group III, ointment containing the OP extract was administered twice a daily. Animals were kept during wound healing for a period of 21 days.

\section{Histopathological studies}

The $1 / 5 \mathrm{~cm}$ skin biopsies were harvested elliptically from burn area on the $3 \mathrm{rd}, 5$ th, 14th and 21 st days. For this purpose, four animals in each group were euthanized at the set time. The samples were fixed in a $10 \%$ formaldehyde solution for $24 \mathrm{~h}$ and later embedded in paraffin blocks. Serial $5 \mu \mathrm{m}$ sections were cut using a rotary microtome. The tissues were stained by haematoxylin and eosin and the number of inflammatory cells, new fibroblast cells, new capillary formation, epithelial cells and collagen fibers formation were counted in 5 high power fields $(\times 100)$ over three separated sections. Assessment was performed by a blinded assessor while considering the histologic grading scale for wound healing, described by Roodbari et al. ${ }^{10}$.

The data was analyzed using Stata 16. All results were presented as means and standard deviations of their respective 
groups. Significance was calculated using analysis of variance and Duncan multiple range test. P value less than 0.05 was considered as significant.

\section{Results}

\section{Histopathological assessments}

On the 3rd day, in all burn-injured groups, there was damage of epidermis, dermis, and subcutaneous adipose tissue as well as some portion of subjacent skeletal muscle tissue; necrotic blood vessels were also observed in the burned region. The inflammation in groups I and II on day 3 was severe in the burn area (Figure 1). Statistically, there were no significantly differences between three groups.

On day 5 , in all groups, the burn causes damages to skin obvious, but in the groups III, the new vessels formation was observed (Figure 2).

The difference in angiogenesis between the control group and group III was statistically significant. Control group showed no distinguishable epithelium and the dermal layer was half the thickness of the adjacent unburned region.

At day 14, the group III displayed the best burn healing results among the other groups. Group I exhibited wounds covered with a thick layer of scar (Figure 3). In comparison, skin sections from groups II and III showed a multilayered epithelium.

On day 21 , in the groups II and III showed relatively well organized epidermal layer and the thickness of epidermal layer. The subcutaneous skeletal muscle organization in the groups II and III was same but in the control groups the dermal compartment had irregularity (Figure 4).

The differences between the fibroblast proliferations of the groups II and III were also not statistically significant.

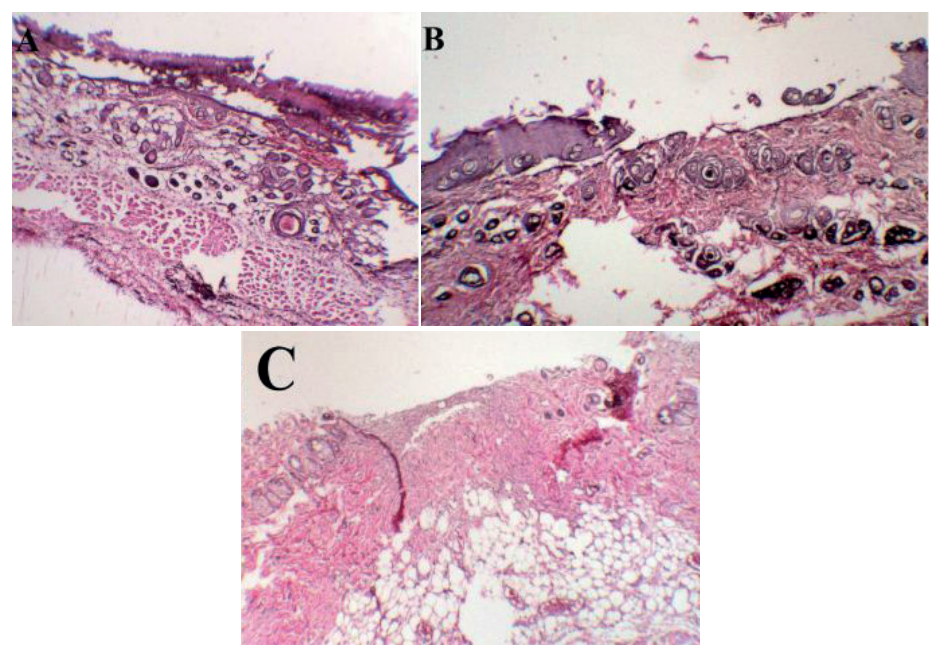

FIGURE 1 - At three days, histological evaluations showed severe damage extending through the dermis in group I (A), group II (B) and group III $(\mathbf{C})$. The dermis showed full-thickness injury and no surviving hair follicles were identified.

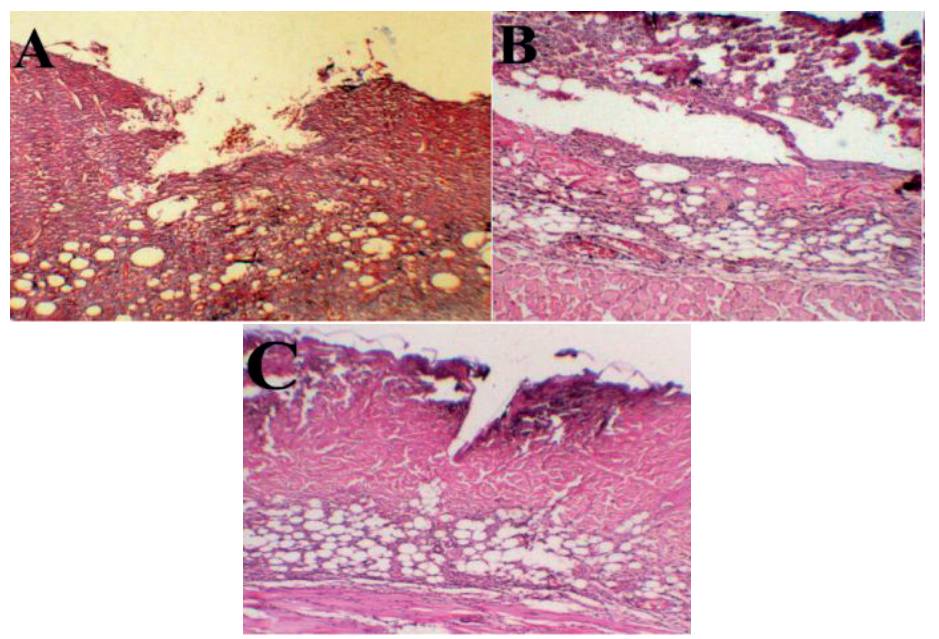

FIGURE 2 - At five days, histological evaluations showed severe damage extending through the dermis in all groups but the number of inflammatory cells decreased in the group II (B) and group III (C) compared to group I (A).

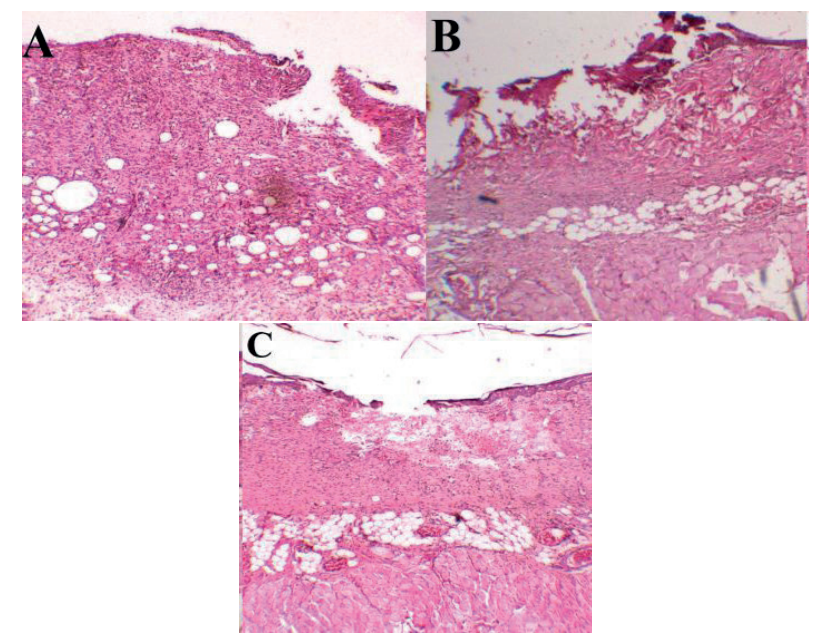

FIGURE 3 - At 14 days, histological evaluations showed. Reepithelialization was observed minimally in the group III (C) and group II (B). Group I (A) showed no distinguishable epithelium. 


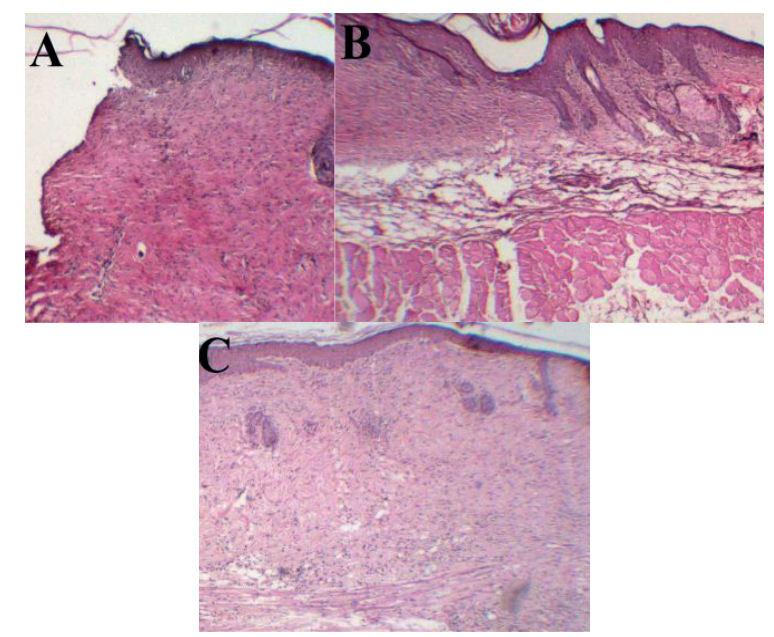

FIGURE 4 - At 21 days, histological evaluations showed Reepithelialization was minimally in the group I (A). The group II (B) and group III $(\mathbf{C})$ showed relatively well organized epidermal layer and the thickness of epidermal layer.

Re-epithelialization in the control group and in group II was lower than in group III. Re-epithelialization in groups II and III was significantly different from that in the control group. Table 1 summarizes the histopathological responses on days 3, 7 and 21 .

TABLE 1 - Skin repair histological scores.

\begin{tabular}{|c|c|c|c|c|c|c|c|c|c|c|c|c|c|}
\hline $\begin{array}{c}\text { Parameter } \\
\text { (maximum score) }\end{array}$ & $\begin{array}{c}\text { Day } \\
\text { Group }\end{array}$ & \multicolumn{3}{|c|}{3 days } & \multicolumn{3}{|c|}{5 days } & \multicolumn{3}{|c|}{14 days } & \multicolumn{3}{|c|}{21 days } \\
\hline \multicolumn{2}{|c|}{ Epithelial cells appearance (3) } & 0.4 & 0.3 & 0.3 & 0.5 & 0.6 & 0.7 & 0.6 & 1.7 & 2.4 & 0.8 & 2.7 & 2.8 \\
\hline \multicolumn{2}{|c|}{ Inflammatory cells Presence (3) } & 0.2 & 0.4 & 0.5 & 0.5 & 0.6 & 0.6 & 0.8 & 1.9 & 1.7 & 1.3 & 2.8 & 3 \\
\hline \multicolumn{2}{|c|}{ New capillary formation (2) } & 0.2 & 0.3 & 0.3 & 0.3 & 0.4 & 0.8 & 0.7 & 1.1 & 1.4 & 0.7 & 1.5 & 1.7 \\
\hline
\end{tabular}

* Group III is significantly different from group I in 5th day, $\mathrm{P}<0.05$.

**Group III is significantly different from group I in 14th day, $\mathrm{P}<0.05$.

*** Group III is significantly different from group I in 14 th day, $\mathrm{P}<0.05$.

\section{Discussion}

Burns are sensitive to infection that may effects on healing of these wounds. Because of its oily and moisturizing features, topical antibiotics are required to promoting burn wound healing and re-epithelialisation ${ }^{11}$. Topical antimicrobial agents containing silver sulfadiazine have been used clinically to eliminate infections common in local burn wounds ${ }^{12}$. Therefore we compared treatment with OP pomade with no treatment and topical treatment alone.

Burn wounds healing are complex process characterized by re-epithelialisation, and granulation tissue formation and remodeling of the burn site ${ }^{9}$. Saving the burn area is a major focus of burn studies. Thermal injury causes excessive inflammation. Neutrophils are the primary inflammatory cells that accumulate on the injured tissue within the first $24 \mathrm{~h}$ after injury ${ }^{13}$. It is thought that antioxidants play a significant role in protecting the living organisms from the toxic effects of chemical substances ${ }^{14}$. Antioxidants are able to suppress the inflammation. According to the experiments, it is determined that methanolic extract of the plant has antioxidant properties ${ }^{8}$. Extract of OP treatment may prevent neutrophil-dependent tissue damage and burn-induced oxidative injury.

Flavonoids are known to promote the wound healing 
process mainly due to their properties such as reducing lipid peroxidation to prevent or slow the onset of cell necrosis, increasing the viability of collagen fibrils by increasing the strength of collagen fibers, preventing the cell damage by promoting the DNA synthesis and increasing the circulation ${ }^{15}$. Generally, Morin as a flavonoid contains antioxidant, anti-allergic, anti-inflammatory, anti-mutation and anti-cancer effects ${ }^{16}$. The antioxidant activity of methnolic extract of OP may be due to Morin in it.

On the 5th day of the experiment, we assessed lower inflammation in the burn area compared to control group. This means that the inflammation was suppressed by methanolic extract of OP, which is essential in the burns healing. Reports in the literature indicate that on day 5, angiogenesis (neo-vascularisation) is established and re-epithelialisation is re-established ${ }^{17}$.

Accordingly in this study from day 5 to 14 , the fibroblast proliferation peaked and was associated with increased collagen accumulation. It was obvious that angiogenesis improved more in the groups II and III, which facilitated re-epithelialisation.

The composition of the methanolic extract of Otostegia persica and the results of our work like dermal regeneration confirmed that the extract had a positive effect towards cellular proliferation, granulation tissue formation and epithelialisation.

\section{Conclusion}

Methanolic extract of Otostegia persica exhibited significant healing activity when topically applied on rats. OP is an effective treatment for saving the burn site.

\section{References}

1. Kufman T, Neuman RA, Weinberg A. Is postburn dermal ischemia enhanced by oxygen free radicals? Burns. 1989;15:291-4.

2. Couladis M, Tzakou O, Verykokidou E, Harvala C. Screening of some Greek aromatic plants for antioxidant activity. Phytother Res. 2003;17:194-6.

3. Linn $\mathrm{CC}$, Wu SJ, Chang Ch. Antioxiant activity of Cinammomum cassia. Phytother Res. 2003;17:726-30.

4. Asgri S, Naderi GA, Bashardoost N, Etminan Z. Antioxidant effect of the essential oil and extract of Matricaria camomilla $\mathrm{L}$ on isolated rat hepatocytes. J Med Plants. 2002;1:9-75.

5. Ayatollahi SAM, Kobarfard F, Asgarpanah J, Choudhari MI. Antiglycation activity of Otostegia persica (Burm) Boiss. Afr J Biotechnol. 2010;9(24):3645-8.

6. Hedayati M, Pouraboli I. The effect of methanolic extract of Otostegia persica on serum glucose level and renal function indicators in streptozotocin induced diabetic rats. Zahedan J Res Med Sci. 2012;14(5):12-5.

7. Ayatollahi SAM, Kobarfard F, Asgarpanah J, Ahmed Z. Chemical constituents from Otostegia persica. J Chem Soc Pak. 2007;29(1):613.
8. Sharififar F, Mozaffarian V, Moradkhani S. Comparison of antioxidant and free radical scavenging activities of the essential oils from flowers and fruits of Otostegia persica Boiss. Pak J Biol Sci. 2007;10(21):3895-9.

9. Shanmuga Priya K, Gnanamani A, Radhakrishnan N, Babu M. Healing potential of Datura alba on burn wounds in albino rats. J Ethnopharmacol. 2002;83:193-9.

10. Roodbari N, Sotoudeh A, Jahanshahi A, Takhtfooladi MA. Healing effect of Adiantumcapillus veneris on surgical wound in rat. Res Opin Anim Vet Sci. 2012;2(12):591-5.

11. Palmieri TL, Greenhalgh DG. Topical treatment of pediatric patients with burns: a practical guide. Am J Clin Dermatol. 2002;3:529-34.

12. Turtay MG, Firat C, Samdanci E, Oguzturk H, Erbatur S, Colak C. Effects of montelukast on burn wound healing in a rat model. Clin Invest Med. 2010;33:413-21.

13. Firat C, Samdanc1 E, Erbatur S, Hamdi Aytekin A, Muharrem AK, Gokhan Turtay M, Kenan Coban Y. $\beta$-Glucan treatment prevents progressive burn ischaemia in the zone of stasis and improves burn healing: an experimental study in rats. Burns. 2013;39:105-12.

14. Sheweita SA, El-Gabar MA, Bastawy M. Carbon tetrachloride changes activity of cytochrome P450 system in the liver of male rats: role of antioxidants. Toxicology. 2001;169:83-92.

15. Imperato F. Sulphate esters of hydroxycinnamic acid-sugar derivative from Adiantum Capillus-Veneris. Phytochemistry. 1982;11:2717-8.

16. Subash S, Subramanian P. Effect of morin on the levels of circulatory liver markers and redox status in experimental chronic hyperanemic rats. Singap Med J. 2008;49(8):650-5.

17. Chan GC, Chan WK, Sze DM. The effects of $\beta$-Glucan on human immune and cancer cells. J Hematol Oncol. 2009;10:2-25.

\section{Correspondence:}

Amin Ganjali

Islamic Azad University

Kahnooj Branch

Kahnooj, Iran

Phone: 00989158378828

Fax: 00983495230203

amin.ganjali@yahoo.com

Received: February 14, 2013

Review: April 16, 2013

Accepted: May 13, 2013

Conflict of interest: none

Financial source: Islamic Azad University

${ }^{1}$ Research performed at Department of Experimental Sciences, Faculty of Experimental Sciences, Islamic Azad University, Kahnooj Branch. 